\title{
Identifying Aspects of Public Attitudes Toward Whole Genome Sequencing to Inform the Integration of Genomics into Care
}

\author{
Holly Etchegary ${ }^{\mathrm{a}}$ Daryl Pullman ${ }^{\mathrm{b}} \quad$ Charlene Simmonds $^{\mathrm{c}}$ Zoha Rabie $^{\mathrm{d}}$ \\ Proton Rahman ${ }^{\mathrm{e}}$ \\ ${ }^{a}$ Assistant Professor Clinical Epidemiology, Faculty of Medicine, Memorial University, St. John's, NL, Canada; \\ bProfessor of Medicine (Bioethics), Faculty of Medicine, Memorial University, St. John's, NL, Canada; 'Manager,

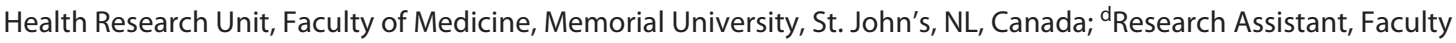 \\ of Medicine, Memorial University, St. John's, NL, Canada; eProfessor of Medicine (Rheumatology), Memorial \\ University and Rheumatologist, Eastern Regional Health Authority, St. John's, NL, Canada
}

\section{Keywords}

Genomics · Genome sequencing · Public attitudes · Survey

\begin{abstract}
Introduction: The growth of global sequencing initiatives and commercial genomic test offerings suggests the public will increasingly be confronted with decisions about sequencing. Understanding public attitudes can assist efforts to integrate sequencing into care and inform the development of public education and outreach strategies. Methods: A 48-item online survey was advertised on Facebook in Eastern Canada and hosted on SurveyMonkey in late 2018. The survey measured public interest in whole genome sequencing and attitudes toward various aspects of sequencing using vignettes, scaled, and open-ended items. Results: While interest in sequencing was high, critical attitudes were observed. In particular, items measuring features of patient control and choice regarding genomic data were strongly endorsed by respondents. Majority wanted to specify upfront how their data could be used, retain the ability to withdraw their sample at a later date, sign a written consent form, and speak to a genetic counselor prior to sequencing. Concerns about privacy and unauthorized access to data were frequently observed. Education level was the sociodemo-
\end{abstract}

karger@karger.com www.karger.com/phg

Karger $\stackrel{\text { ' }}{5}$

bOPEN ACCESS
(C) 2021 The Author(s)

Published by S. Karger AG, Basel

This is an Open Access article licensed under the Creative Commons Attribution-NonCommercial-4.0 International License (CC BY-NC) (http://www.karger.com/Services/OpenAccessLicense), applicable to the online version of the article only. Usage and distribution for commercial purposes requires written permission. graphic variable most often related to attitude statements such that those with higher levels of education generally displayed more critical attitudes. Conclusions: Attitudes identified here could be used to inform the development of implementation strategies for genomic medicine. Findings suggest health systems must address patient concerns about privacy, consent practices, and the strong desire to control what happens to their genomic data through public outreach and education. Specific oversight procedures and policies that are clearly communicated to the public will be required.

(c) 2021 The Author(s) Published by S. Karger AG, Basel

\section{Introduction}

Whole genome and exome sequencing (WGS/WES) are increasingly being used for treatment and diagnostic indications in oncology and rare disorders [1-3] and also in susceptibility testing and identifying risks for common diseases [4]. Private companies continue to market a variety of personal genomic tests (so-called direct to consumer tests) that provide health-related information, such as risks for common conditions or response to medications (pharmacogenomics), and also social informa- 
tion related to sporting ability, personality traits, or even choice of dating partner $[5,6]$. Genomic data are being generated more quickly and less expensively than ever; coupled with high levels of public interest and expectations for sequencing [7-9], the integration of genomics is being felt across more and more healthcare specialities [10].

There are considerable challenges to the integration of genomics into clinical practice, however. The sheer volume of data generated from WGS, the clinical utility of results, the return of unexpected or incidental findings, the availability of structures and processes to support the use of genomic data in clinical care, as well as patient and provider ability to understand and appropriately act on sequencing results are some of the concerns highlighted in the literature $[1,3,7-12]$.

Despite the challenges, genomic medicine initiatives continue to be implemented globally with billions of dollars of government investment [13]. More and more members of the general public are exposed to sequencing and could have to make decisions about sequencing in their healthcare. The translation of genomic tests into practice will be influenced strongly by demonstrations of clinical utility and also by public attitudes and interest $[1$, 6]. Understanding public opinion and attitudes can help shape emerging genomic services and inform education and engagement efforts for both the public and their care providers.

\section{Study Context and Aims}

As part of informing planning for how genomic testing will be implemented in our healthcare system, we began a program of public engagement in late 2018 that included the following: (1) establishing a public advisory council on genomics [14]; (2) public town hall sessions; and (3) an online provincial survey.

We previously reported some survey findings which revealed high levels of interest in sequencing and areas of information identified by the public as necessary to inform sequencing decisions [7]. Here, we focus specifically on public attitudes. A recent review by the American College of Human Genetics [15] revealed little change in the literature over several years, determining that public attitude toward genetics and genomics research was very positive, despite low levels of genomic knowledge. However, the review noted that many studies to date "have not fully explored aspects of attitudes that may have implications for genetic health services or policies" $[15$, p. 5]. We aim to contribute to that gap in the literature and provide descriptive, attitudinal data that can inform the integration of genomics into clinical care in ways that accord with the public who will ultimately use the service.

\section{Materials and Methods}

This project received ethics approval from the provincial Health Research Ethics Board (Ref \# 2018.221).

Study Setting

This study took place in the Atlantic province of Newfoundland and Labrador (NL), Canada. Healthcare services are publicly funded and provided by 4 regional health authorities: Eastern Health (the largest and urban health authority), Central Health, Western Health, and Labrador-Grenfell Health (serving largely rural populations).

\section{Survey Administration and Sample Selection}

The online survey was administered on SurveyMonkey over 2 weeks in late 2018, and paid advertising enabled advertising of the survey link on Facebook. During the first week, Facebook advertised the survey link to all registered users in the province. In the second week, targeted advertising was implemented as needed (e.g., to underrepresented users in the rural health authorities). The survey link was also shared widely through the research team's and public council's personal and professional networks, communication channels of Memorial University, and the provincial health authorities.

\section{Survey Development and Content}

We created a 48-item survey (available upon request) that included of a mix of vignettes, scaled, open-ended, and demographic items. The survey began with an explanation of WGS and a summary of its potential risks and benefits. Survey items measured the following: (1) interest in WGS and information preferred for sequencing decisions, (2) interest in pharmacogenomic testing specifically, (3) attitudes toward various features of genome sequencing, (4) preferences for the return of incidental findings, (5) opinions about the secondary use of genomic data, and (6) demographic items.

Descriptions and explanations of pharmacogenomics, genome sequencing, data sharing, and related items used in the survey were modified or taken from several similar studies or relevant websites such as Genome England [16-23]. Survey development took place over 2 months, with several iterations among the project team, clinical staff at the Provincial Medical Genetics Program, and the Public Advisory Council on genomics [14]. Public council members in particular identified survey language and wording that they felt would not be understood by a general public sample and suggested alternative wording for items. While the survey was not formally pilot-tested before administration, all 12 members of the public council read multiple versions of the survey and were invited to share the survey with their contacts for additional feedback. In this article, we focus largely on the third survey section attitudes toward various aspects of genomics.

All attitude items $(n=15)$ were measured on a 5-point Likert scale from strongly agree (1) to strongly disagree (5). Items were reverse-scored such that higher scores indicate greater agreement 
Table 1. Demographic information of survey respondents

\begin{tabular}{|c|c|c|}
\hline Demographic item (total $N$ ) & Variable levels & Total N (\%) \\
\hline \multirow[t]{2}{*}{ Sex $(694)$} & Male & $172(24.8)$ \\
\hline & Female & $517(74.5)$ \\
\hline \multirow[t]{4}{*}{ Health authority of residence (692) } & Eastern & $494(73.5)$ \\
\hline & Central & $78(11.6)$ \\
\hline & Western & $82(12.2)$ \\
\hline & Labrador-Grenfell & $18(2.7)$ \\
\hline \multirow[t]{4}{*}{ Highest level of education completed (688) } & High school or less & $77(11.2)$ \\
\hline & Trade school/college diploma & $246(35.8)$ \\
\hline & University, undergraduate & $181(26.3)$ \\
\hline & University, graduate degree & $184(26.7)$ \\
\hline \multirow[t]{4}{*}{ Annual household income (671) } & $<$ USD 20,000 & $44(6.6)$ \\
\hline & USD $20,000-40,000$ & $89(13.3)$ \\
\hline & USD $40,000-60,000$ & $116(17.3)$ \\
\hline & $>$ USD 60,000 & $422(62.9)$ \\
\hline \multirow[t]{3}{*}{ Marital status (691) } & Married & $459(66.4)$ \\
\hline & Single & $145(21)$ \\
\hline & Divorced, separated, and widowed & $87(12.6)$ \\
\hline \multirow[t]{3}{*}{ History of genetic condition in family (693) } & Yes & $304(43.9)$ \\
\hline & No & $175(25.3)$ \\
\hline & Unsure & $214(30.9)$ \\
\hline \multirow{2}{*}{$\begin{array}{l}\text { Have you ever used direct-to-consumer genetic } \\
\text { testing such as } 23 \text { andMe or ancestry.com? (697) }\end{array}$} & Yes & $93(13.3)$ \\
\hline & No & $604(86.7)$ \\
\hline \multirow[t]{2}{*}{ Have you ever had genetic counseling? (695) } & Yes & $88(12.7)$ \\
\hline & No & $697(87.3)$ \\
\hline
\end{tabular}

with item statements. Interest in sequencing was measured with one item on a 5-point scale from definitely interested (1) to definitely not interested (5), reverse-scored so that higher scores indicate greater levels of interest in pursuing sequencing. One open-ended attitude item asked respondents for any additional comments about what they would like to know about in relation to WGS.

\section{Data Analysis}

Descriptive analysis included frequencies, means, and standard deviations for all attitude items. A correlational analysis explored univariate relationships among all attitude items and demographic/social variables (Table 1), as well as attitude items' relationship with the interest in sequencing item. Significant attitude items were entered into a logistic regression, where the interest item was recoded into a binary outcome measure (interested in sequencing vs. not interested in sequencing), while controlling for demo-

Public Attitude Toward Whole Genome Sequencing graphic variables. These included age in years, sex, marital status, number of children, education level, range of annual household income, as well as prior experience with direct-to-consumer genomic testing, prior experience with genetic counseling, and selfreported family history of a genetic condition.

\section{Sample Size}

At the $95 \%$ confidence interval, a sample size of 600 is required to be confident in descriptive survey results within \pm 4 percentage points (https://www.surveysystem.com/sscalc.htm).

The open-ended attitude item was analyzed by H.E. and Z.R., incorporating principles of constant comparison and qualitative description [24, 25]. Analysis was based on 195 unique survey comments. Answers to the open-ended item were placed in a $\mathrm{Mi}$ crosoft Word table, where respondent comments were first read and re-read independently by the 2 team members to begin iden- 
Table 2. Percent endorsing response options, mean, and standard deviation of attitude survey items

\begin{tabular}{|c|c|c|c|c|c|c|c|}
\hline Item & $\begin{array}{l}\text { Strongly } \\
\text { agree }\end{array}$ & Agree & Neutral & Disagree & $\begin{array}{l}\text { Strongly } \\
\text { disagree }\end{array}$ & Mean* & $\mathrm{SD}^{*}$ \\
\hline $\begin{array}{l}\text { I would want my family doctor to have information about my sequencing results } \\
\text { to inform decisions about my care }(N=733)\end{array}$ & 57.0 & 30.2 & 7.2 & 3.7 & 1.9 & 4.4 & 0.91 \\
\hline $\begin{array}{l}\text { If I had my genome sequenced, I would share my results with other family } \\
\text { members who might also be affected }(N=733)\end{array}$ & 50.1 & 34.1 & 12.7 & 1.5 & 1.6 & 4.3 & 0.87 \\
\hline $\begin{array}{l}\text { I would be concerned that a genomic test would cause problems with insurance } \\
(N=733)\end{array}$ & 50.2 & 25.0 & 15.3 & 7.4 & 2.2 & 4.1 & 1.1 \\
\hline $\begin{array}{l}\text { Before having my genome sequenced, I would want some control over who I } \\
\text { allowed access to my sequencing results }(N=732)\end{array}$ & 76.0 & 18.7 & 3.8 & 0.8 & 0.7 & 4.7 & 0.65 \\
\hline $\begin{array}{l}\text { I would be concerned that a genomic test would cause problems with } \\
\text { employment }(N=734)\end{array}$ & 21.0 & 21.8 & 24.3 & 22.2 & 10.8 & 3.2 & 1.3 \\
\hline $\begin{array}{l}\text { It is important my healthcare provider tell me about any genomic tests before } \\
\text { they are done }(N=720)\end{array}$ & 77.6 & 19.3 & 2.1 & 0.8 & 0.1 & 4.7 & 0.55 \\
\hline $\begin{array}{l}\text { If I had my genome sequenced as part of a research study, I would want the } \\
\text { ability to withdraw my genomic sample from the study if I later changed my } \\
\text { mind }(N=720)\end{array}$ & 50.0 & 22.8 & 14.0 & 9.6 & 3.6 & 4.1 & 1.2 \\
\hline $\begin{array}{l}\text { I would have my genome sequenced if it could help me learn about my risks for } \\
\text { future diseases that are not currently treatable }(N=718)\end{array}$ & 51.3 & 25.8 & 11.6 & 7.9 & 3.5 & 4.1 & 1.1 \\
\hline $\begin{array}{l}\text { If I had my genome sequenced, I would prefer to sign a written consent form } \\
\text { about how my sample could be used }(N=717)\end{array}$ & 67.2 & 24.5 & 6.3 & 1.4 & 0.6 & 4.6 & 0.72 \\
\hline $\begin{array}{l}\text { Based on the information covered in this survey, how interested are you in } \\
\text { getting your whole genome sequenced? }(N=697)^{* *}\end{array}$ & 55.8 & 29.0 & 7.7 & 4.7 & 2.7 & 4.3 & 0.99 \\
\hline
\end{tabular}

* Mean and standard deviation (SD) after all items were reverse scored such that higher scores indicate greater agreement with items. ${ }^{* *}$ Response scale for this item: a 5 -point scale, where 1 = definitely interested and $5=$ definitely not interested, reverse scored so that a higher value indicates greater interest.

tifying emerging categories and themes [25]. While a formal codebook was not developed, discussion between the analysts following the coding of the first 60 open comments revealed very similar and consistent codes emerging (e.g., motivations for testing and privacy concerns). Once independent coding of all 195 responses was complete, investigators met again to discuss coding decisions. While we did not formally calculate interrater reliability statistics, codes were very similar ( $>90 \%$ agreement); differences tended to be minor wording issues (e.g., "concerns about privacy of genomic data" vs. "worried about who could access genomic data") and were resolved through discussion.

\section{Results}

\section{Survey Response and Missing Data}

Just over $1,000(n=1,028)$ individuals opened the survey link as measured by the survey platform, with 901 answering the first question measuring interest in sequencing [7]. Because we do not know how many people ultimately saw the study invitation and declined to participate, an accurate response rate is unavailable. It was 
evident that responses to individual items lessened as the survey continued, with just below 700 answering the final items. Respondent burden was possible toward the end of the survey, given its length and complexity. We report the total $n$ for each item and analysis presented.

\section{Respondents}

Respondents were 45 years old on average (standard deviation $[\mathrm{SD}]=13.9$; range $=18-82$ years). Most were female and lived in the largest health authority, with smaller numbers from the more rural authorities (Table 1). Most were married and had a least 1 child (mean $=1.3 ; \mathrm{SD}=1.2)$, a university degree, and annual incomes of more than USD 60,000. Over 40\% reported a genetic condition in their families, but very few reported having experience with genetic counseling (just over $12 \%$, Table 1). Approximately $13 \%$ had used direct-to-consumer genomic services.

\section{Attitude toward Genome Sequencing}

Table 2 displays the descriptive analysis of attitude items, including the percentage of respondents who endorsed each scale response. A majority had a favorable attitude toward sequencing, even for disorders not currently treatable. However, descriptive statistics revealed several nuanced aspects of public attitude about genome sequencing. For example, majority would share the results of sequencing with their family doctors and their family members, but a much lower percentage of respondents would share sequencing results with pharmacists. Over half of the respondents endorsed that if sequencing revealed something unexpected, it might cause worry; a sizable majority also worried sequencing could cause problems with insurance, and some worried it might cause problems with employment. Majority indicated they would want control over who could access their results, how their sample could be used, and the ability to withdraw their sample at a later date, and would prefer to sign a written consent form before sequencing. In keeping with this notion of patient control, majority of the respondents indicated they would want to know what testing was being done before the testing and would want the option to talk to a genetic counselor a priori. A majority disagreed that we worry too much about privacy and genetics.

We previously reported high levels of interest in genome sequencing in this sample [7], with almost $60 \%$ definitely interested and over $20 \%$ somewhat interested in having their genomes sequenced at the beginning of the survey. In this analysis, we report interest levels at the end

Public Attitude Toward Whole Genome Sequencing of the survey - after all other items had been presented. Interest remained high and virtually unchanged at the end of the survey (Table 2).

Table 3 displays correlations among all attitude items and interest in sequencing, as well as with the demographic and social variables. Regarding the latter, education level and income were most often associated with attitude items. In general, those with the highest levels of education and income were less likely to share the results of sequencing with their care providers and family members. Additionally, agreement with attitude items measuring notions of patient control and choice about sequencing were also positively related to income and education; those with the highest levels of income and education strongly endorsed patient control over sequencing, preferred to sign a written consent form before sequencing, and agreed people should have genetic counseling before sequencing. Concerns about insurance and employment impacts of sequencing were also positively related to education and income levels. The latter were negatively related to attitude toward sequencing for disorders that are currently not treatable and to the item measuring the value of concerns about privacy. Essentially, the pattern of correlations revealed that despite overall interest in sequencing being high, those with the highest levels of education and income expressed more critical attitudes toward several aspects of sequencing.

Those who indicated they had used direct-to-consumer testing were less likely to agree with sequencing for disorders that are currently not treatable (Table 3). Women were more likely than men to agree genetic counseling was needed prior to sequencing and that they would worry sequencing could return unexpected results. They were also more likely to agree with the statement about wanting to have the ability to withdraw their sample if they later changed their mind about sequencing. However, it is clear that majority of the respondents agreed with these statements, and the correlations with sex were small.

Table 3 also reveals that all the attitude items were related to interest in sequencing. These relationships were in expected directions. For example, those who endorsed sharing their sequencing results with care providers and family members and those with favorable attitudes toward sequencing for disorders that were not treatable were more likely to express interest in sequencing. Those who were more worried about unexpected results or had employment or insurance concerns were less likely to express interest in sequencing. Agreement with attitude items measuring some aspect of patient control and choice about sequencing, as well as believing patients

Public Health Genomics 2021;24:229-240 


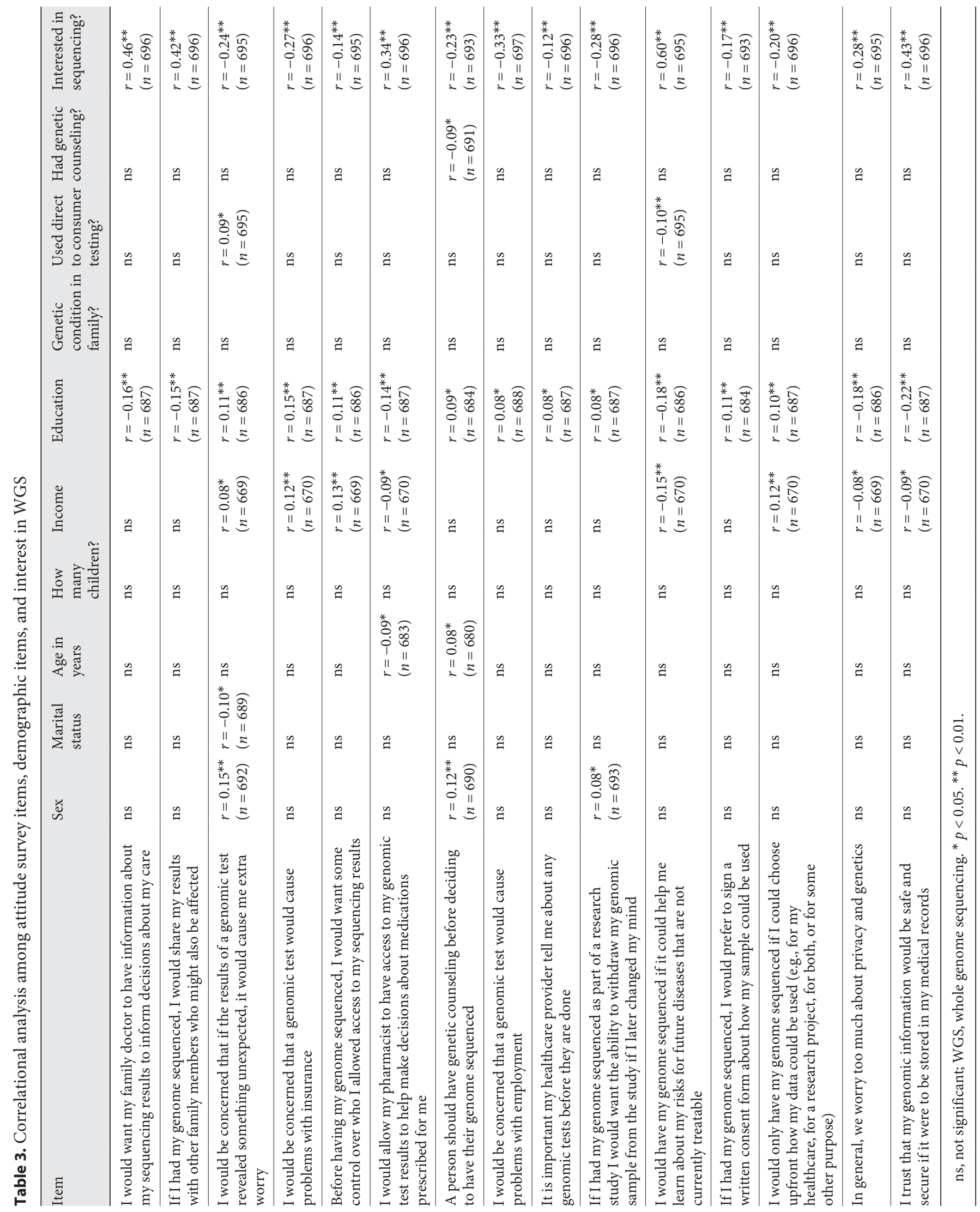


Table 4. Logistic regression predicting interest in sequencing from demographic and attitude items

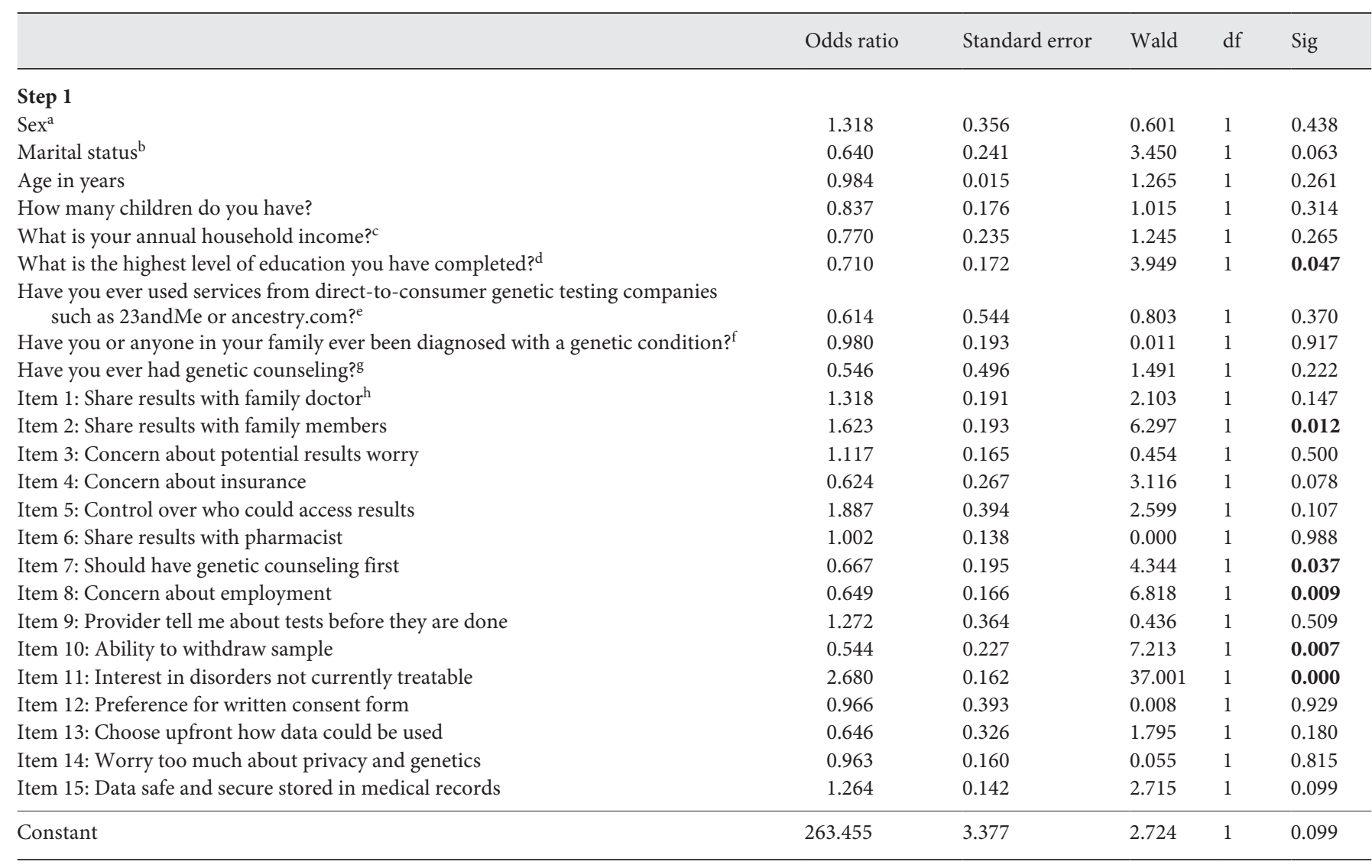

${ }^{a}$ Males. ${ }^{b}$ Divorced/separated/widowed/never married. ${ }^{\mathrm{c}}>$ USD $60,000 .{ }^{\mathrm{d}}$ College degree or less. ${ }^{\mathrm{e}}$ Yes. ${ }^{\mathrm{f}}$ Yes. ${ }^{\mathrm{g}}$ Yes. ${ }^{\mathrm{h}}$ Unsure/disagree/strongly disagree for all attitude item predictors. Bolded values indicate statistical significance.

should have access to genetic counseling prior to sequencing and should sign a written consent form, revealed negative correlations, indicating less interest in sequencing.

Logistic regression was used to identify aspects of attitudes related to interest in sequencing while controlling for demographic variables. Controlling for age, sex, marital status, number of children, income level, and education level; having a genetic condition in the family; having previously used direct-to-consumer genomic testing; and having ever had genetic counseling revealed 5 attitude items that remained related to interest in sequencing; education level was the sole significant demographic predictor, albeit with a small beta value (Table 4 ). The model was significant $\left(\chi^{2}[24]=239.6, p=000\right)$.

Table 4 reveals that those who indicated they were interested in sequencing for disorders not currently treatable were more than 2 times as likely to indicate interest in sequencing overall; those who indicated they would share sequencing results with family members were 1.6 times as likely to indicate overall interest in WGS. Again, those with the highest levels of education were less likely to indicate interest in sequencing, while those who would worry sequencing might have impacts on employment, those who agreed people should see a genetic counselor before sequencing, and those who would want the ability to withdraw their genomic sample from research were less likely to indicate interest in sequencing, although these attitude items contributed less variance in the interest outcome.

Analysis of the open-ended attitude item revealed sequencing motivations, but also concerns. Respondents were asked the kinds of information they would want to know about if they were considering having their genome sequenced; 195 survey respondents provided comments. Figure 1 reveals their sequencing motivations of discovering more about the family history of disease, ancestry, and risk for future conditions; however, just over half would 
Fig. 1. Coding of open comments. The figure displays key themes that arose from coding responses to the question, "What information would you want to know about in deciding about genome sequencing?" ( $n=195$ unique comments). Information desired related to privacy, data access, and storage and motivations for sequencing.

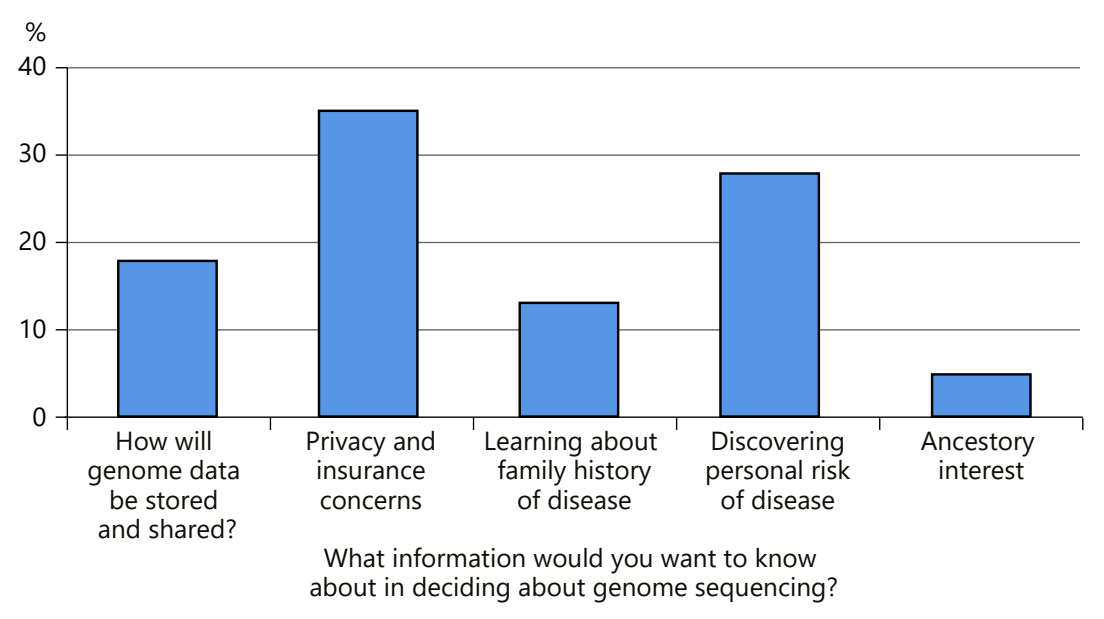

What information would you want to know also want information about the protection and privacy of their genome data, as well as information on how/if insurance companies would have access to their sequencing results.

Table 5 displays representative comments for each of the coding categories.

\section{Discussion/Conclusions}

The growth of national sequencing initiatives and continued marketing of direct-to-consumer personal genomic tests suggest the public will increasingly be making decisions about sequencing. Understanding public attitudes and opinions can help inform efforts to integrate sequencing into care and assist with the creation of public education and outreach interventions. Survey findings revealed high levels of interest in sequencing and motives for sequencing revolving around understanding family history of disease and discovering personal risk for future disease, consistent with other studies $[4,9,11,15,16]$. Here, however, we wish to focus on results that highlight specific aspects of attitudes that should be helpful for decision makers and planners of genomic medicine services. In particular, findings reveal potential areas of public preferences regarding the delivery of genomic services and attributes of the service that matter to them.

For example, majority of the respondents would want their family doctors to have access to their sequencing results to inform their care, but a lower percentage would share results with pharmacists. This is a notable difference having implications for how genomic information is stored, accessed, and used in care, particularly pharmacogenomic information. Pharmacogenomics might be considered the "low-hanging fruit" of personalized medicine, described by proponents as a relatively uncomplicated and near-immediate application [26]. We previously reported high interest in pharmacogenomic testing in this sample [7], consistent with other public attitudinal research $[27,28]$. However, even in these samples with high levels of interest, the public expressed concerns about the privacy and confidentiality of their pharmacogenomic information [27]. Research with chronically ill patients [29] and those with mental health conditions [30] revealed especially strong concerns about potential discrimination. Those studies also revealed patient preferences for a holistic approach to therapeutic decisions, not one guided solely by genomic information.

We cannot explain why respondents were less likely to endorse sharing their sequencing results with pharmacists than family doctors. It is reasonable to assume that patients have closer and potentially life-long relationships with their family doctors, and as such, are more comfortable with those providers having access to their health information, including sequencing results (and indeed likely expect their family doctors to have access). Like other patients $[29,30]$, perhaps our respondents also have concerns about discrimination and privacy in the pharmacy setting. Whatever the reason, this descriptive finding cautions planners of genomic services to be transparent with the public about what provider(s) results will be shared and when. There is evidence that patients support restricted provider access to their genomic data relevant to current clinical concerns [30], and therapeutic 
Table 5. Themes and quotes arising from analysis of the open-ended attitude item

\begin{tabular}{ll}
\hline Theme & Representative, unique comments from open item $(n=195)$ \\
\hline $\begin{array}{l}\text { How will my genome } \\
\text { data be stored and } \\
\text { shared? }\end{array}$ & $\begin{array}{l}\text { Anonymity of data and use by unauthorized parties would be of significant concern } \\
\text { How my sample and results would be stored and for what period of time }\end{array}$ \\
& $\begin{array}{l}\text { I am concerned about who might have access to this genomic information in the future } \\
\text { I just want to have control and be asked each time when my data are used. Not just a one-time, unlimited } \\
\text { Storage of my DNA. Can it be sold in the future? }\end{array}$
\end{tabular}

Privacy and insurance Could my information be sold to or used by anyone else? Could insurance companies refuse coverage or inconcerns crease premiums based on my results?

How do privacy laws protect my data? Could information be used by insurance companies? Where the data are stored, that is, to ensure Canadian laws protect Canadians and that there was no risk of another country having access to the specific data linked to me

I worry about the impacts of having my genomic information available and its potential impacts on insurances such as health, critical illness, and life. Would I have to disclose? What if there was a mutation that is not yet known what its impact is? Will it impact my children and their insurance rates?

Privacy of data should be paramount - we are not known for our robust security measures. How would participants control where their genetic information goes after the initial study?

\begin{tabular}{ll}
\hline Motivation - family & What diseases run in my family? \\
history of disease & Health issues that have shown up on both sides of my family \\
& I have a high family history of breast cancer, that is what interests me \\
& My maternal and paternal side has heart disease. I am not afraid of information, especially if I can act pre- \\
& emptively \\
& Why is there so much heart disease in my family?
\end{tabular}

Motivation - personal Can genomes tell you if you are predisposed to life-threatening diseases?

risk of disease $\quad$ First and foremost, I want to know the medical trends that am I predisposed to

If I would be prone to cancer or heart disease

Not only is this ethical, I believe it is necessary. I had sequencing results and learned about a medical condition I have, which is curable

I would not want to know about dementia, but I would want to know about heart disease, or things that I could do something about

Motivation - ancestry Where do my ancestors come from?

interest Information into ancestry would be nice

decisions might be an area where restricted access would be permissible. Future research could more narrowly explore patient perceptions and preferences for restricted access, rather than ask about broad interest in pharmacogenomics testing as we did here.

Concerns about genomic data storage, sharing, priva$c y$, and unauthorized access are common in the literature $[6,15,30-32]$. Our findings are in line with that research but also reveal some specific preferences and concerns. For example, while half of our respondents agreed their genomic data would be secure if stored in the electronic medical record, a quarter disagreed with this statement, and a sizable minority were unsure. The open comments also revealed concerns about insurance companies or others not bound by Canadian privacy laws accessing genomic data. Concerns were noted about future uses of genomic data, and preferences for ongoing consent were revealed. Despite high levels of interest in sequencing, majority of our respondents strongly agreed with all attitude items that measured some aspect of patient control and choice over their sequencing samples and results.

These findings have implications not only for the implementation of preferred consent models in sequencing, but also specifically for patient and public education and consent documents. Our findings suggest very clear and transparent information must be provided - preferably prior to sequencing - about where samples will be stored, for how long, who will have access, withdrawal policies (if withdrawal is possible at all), how samples will be used (clinically and in research), and by whom. We also suggest including information on local or national legislation (e.g., in Canada, Bill S-201, the Genetic Non-Discrimina- 
tion Act) that might inform potential users of sequencing of relevant privacy laws and their implications.

Our findings also reveal respondent preferences to withdraw genomic samples if they so choose, to decide upfront to what uses their genomic data can be put, and to have control over their genomic data; these preferences are in line with dynamic consent models [33]. Such models generally refer to personalized, online consent and communication platforms [34]. These afford patients the control to specify preferences regarding their personal health data; attend to as little or as much consent information as they wish, at their own pace; and also specify when and how they wish to be contacted about the use of their personal health information. Dynamic consent models have been used in recent genomics initiatives (e.g., [35]) and could accord well with public and patient demand for control of their genomic data. They are potentially contradictory, however, with public preferences for signing a written consent form about uses of their genomic data. Over two-thirds of our respondents strongly agreed with providing written consent before sequencing. We do not know if this attitude is ultimately incompatible with dynamic consent platforms or if it is the case that written modes of consent are perceived as safer or affording more patient control. Future research would be valuable here. Nonetheless, this preference implies that if at all possible, choice of how to give consent for sequencing and the use of genomic data would likely be perceived as valuable by the public.

In line with research with patients $[32,36]$, a sizeable majority of our public respondents endorsed receiving genetic counseling before undergoing sequencing. Accommodating this patient preference would have significant resource implications for healthcare systems, particularly in light of the well-documented lack of specialized genetic counseling services [37]. Healthcare funders and planners of genomic medicine services need to carefully consider the availability of access to genetic counselors before sequencing is introduced into routine clinical practice. Research shows patients are open to alternatives to traditional, face-to-face genetic counseling, such as group sessions or over the telephone $[28,38]$, and recently through online platforms [39]. Such alternatives to face-to-face, individual sessions might offer a compromise between patients' desire for genetic counseling and the healthcare system's lack of resources to provide it. Future research on education and counseling strategies for genomic information would be very valuable to inform the implementation of genomics into routine practice.
Respondent attitudes were related to few sociodemographic variables, but most often to level of education, and it remained significant in the regression model. Consistently, those with higher levels of education expressed more critical attitudes toward various aspects of genomic sequencing. This might suggest an increased ability to think critically about ethical and clinical utility aspects of genomic information and promote informed decisions, raising questions about equity and informed access to genomic medicine. However, recent reviews of research on public and provider understanding highlight significant comprehension difficulties with genomic concepts and terminology $[15,36]$, and suggest efforts to increase genomic literacy more broadly are needed. Research that creates and tests interventions to support the use of information related to genomic testing could help ensure realistic expectations for sequencing and promote informed sequencing decisions.

There were several limitations to this study, notably to the representativeness of respondents. Survey respondents were white, well-educated, with high annual incomes; they were recruited largely through Facebook advertising which may not be generalizable to those who do not use such social media platforms and likely skewed respondent demographics toward active Facebook users. A recent provincial survey administered on Facebook did show successful recruitment of a partially representative sample when compared to provincial statistics [40], and revealed similar challenges and biases to traditional recruitment of survey samples. NL has a high proportion of its population using Facebook; the Atlantic provinces have the highest Facebook usage in Canada, with 94\% using Facebook and $73 \%$ using it daily [41]. Nonetheless, survey findings must be interpreted with caution as respondents recruited via Facebook are not representative of the general population; furthermore, our method of recruitment does not allow us to provide a comparison of respondents and nonrespondents.

There was a lack of diversity in study respondents with those of lower education and income levels not adequately represented. High levels of interest in sequencing were observed in this sample, suggesting findings may only be generalizable to those already positively inclined toward sequencing. However, as noted, many critical attitudes were expressed by respondents. The survey instrument was long, and we observed significant drop off in responses from the first item to the last. We cannot know if or how the survey length and complexity impacted the nature of responses. Pilot testing of the survey instrument could have potentially helped ensure higher completion 
rates. Finally, as in all surveys, the potential for response bias may exist from the survey items themselves (e.g., we cannot determine if respondents expressed concerns or agreement with statements simply because they were asked to consider them on the survey, nor can we know how concerns expressed through agreement with survey items compare to any other concerns of respondents).

\section{Conclusions}

There is no clear model of how genomic services are (or will be) offered to patients. Opinions identified here could be used to inform the development of implementation strategies for incorporating genomic risk information into clinical practice and ensure implementation outcomes such as patient preferences and acceptability are considered [42]. Findings suggest health systems considering integrating genomic sequencing must address patient concerns about privacy, consent practices, and the strong desire to control what happens to their genomic data through public and patient outreach and education. Transparent and specific oversight procedures and policies that are clearly communicated to the public will also be required.

\section{Acknowledgements}

We thank survey respondents for their time and responses. We are also grateful to Dr. Brenda Wilson, Professor, Community Health and Humanities, Faculty of Medicine, Memorial University for input on the survey design and content.

\section{Statement of Ethics}

The authors state that institutional review board approval was granted for this study through the Health Research Ethics Board, St. John's, NL, Canada (Approval \# 2018.221). Informed consent was obtained from the participants involved at the beginning of the online survey. Respondents could not begin the survey before reading the consent pages and ticking an appropriate check box. Consent was implied if respondents ticked the box and submitted a survey.

\section{Conflict of Interest Statement}

The authors have no conflicts of interest to declare.

\section{Funding Sources}

Funding support for this study was provided by the Atlantic Canada Opportunities Agency Business Development Program to Rahman. The funder had no role in the conduct of the study, collection, and analysis of data or writing of the manuscript.

\section{Author Contributions}

H.E., P.R., and D.P. contributed substantially to the conception and design of the work; C.S. contributed to the design of the work and substantially to the acquisition of data for the work; H.E. did the quantitative data analysis; Z.R. and H.E. did the qualitative data analysis; H.E. drafted the manuscript; all authors revised it critically for intellectual content; and all authors gave final approval of the version to be published.

\section{References}

1 Krier JB, Kalia SS, Green RC. Genomic sequencing in clinical practice: applications, challenges, and opportunities. Dial Clin Neurosci. 2016;18(3):299-312.

2 Sabour L, Sabour M, Ghorbian S. Clinical applications of next-generation sequencing in cancer diagnosis. Pathol Oncol Res. 2017; 23(2):225-34

3 Zhang H, Klareskog L, Matussek A, Pfister SM, Benson M. Translating genomic medicine to the clinic: challenges and opportunities. Genome Med. 2019;11(1):9.

4 Zoltick ES, Linderman MD, McGinniss MA, Ramos E, Ball MP, Church GM, et al. Predispositional genome sequencing in healthy adults: design, participant characteristics, and early outcomes of the PeopleSeq consortium. Genome Med. 2019;11(1):10.

5 Hogarth S, Saukko P. A market in the making: the past, present and future of direct-to-con- sumer genomics. New Genet Soc. 2017;36(3): 197-208.

6 Metcalfe S, Hickerton C, Savard J, Terrill B, Turbitt E, Gaff C, et al. Australians' views on personal genomic testing: focus group findings from the Genioz study. Eur J Hum Genet. 2018;26:1101-12.

7 Etchegary $\mathrm{H}$, Wilson B, Rahman P, Simmonds C, Pullman D. Public interest in whole genome sequencing and information needs: an online survey study. Per Med. 2020;17(4):283-93. online ahead of print.

8 Bernhardt BA, Roche MI, Perry DL, Scollon SR, Tomlinson AN, Skinner D. Experiences with obtaining informed consent for genomic sequencing. Am J Med Genet A. 2015; 167A(11):2635-46.

9 Hull LE, Vassy JL. Toward greater understanding of patient decision-making around genome sequencing. Per Med. 2018;15(1):5766.

10 Josephs KS, Berner A, George A, Scott RH; Health Education England's Genomic Education Programme, Firth HV, et al. Genomics: the power, potential and pitfalls of the new technologies and how they are transforming healthcare. Clin Med. 2019;19(4): 269-72.

11 Roberts J, Robinson J, Diamond P, Bharadwaj A, Christensen K, Lee K, et al. Patient understanding of, satisfaction with, and perceived utility of whole genome sequencing: findings from the MedSeq project. Genet Med. 2018; 20(9):1069-76.

12 Hallowell N, Hall A, Alberg C, Zimmern R. Revealing the results of whole genome sequencing and whole exome sequencing in research and clinical investigations: some ethical issues. J Med Ethics. 2015;41(4):317-21.
Public Attitude Toward Whole Genome Sequencing
Public Health Genomics 2021;24:229-240 
13 Stark Z, Dolman L, Manolio TA, Ozenberger B, Hill SL, Caulfied MJ, et al. Integrating genomics into healthcare: a global responsibility. Am J Hum Genet. 2019;104(1):13-20.

14 Abhyankar S, Etchegary H. Rolling out genomic screening: the Newfoundland and labrador public advisory council on genomics (PACG). BMJ Partnership Pract Ser. 2019. Available from: https://blogs.bmj.com/bmj/ 2019/12/17/rolling-out-genomic-screening/

15 American Society of Human Genetics [Internet]. Public attitudes toward genetics \& genomics research: literature and polling review report. 2020 [cited 2020 June 9]. Available from: https: //www.ashg.org/wp-content/ uploads/2020/01/2020-Public-Views-Genetics-Literature-Review.pdf.

16 Dodson DS, Goldenberg AJ, Davis MM, Singer DC, Tarini BA. Parent and public interest in whole-genome sequencing. Public Health Genomics. 2015;18(3):151-9.

17 Zhang SC, Bruce C, Hayden M, Rieder MJ. Public perceptions of pharmacogenetics. Pediatrics. 2014;133(5):e1258-67.

18 Brothers KB, East KM, Kelley WV, Wright MF, Westbrook MJ, Rich CA, et al. Eliciting preferences on secondary findings: the preferences instrument for genomic secondary results. Genet Med. 2017;19(3):337-44.

19 Townsend A, Adam S, Birch PH, Lohn Z, Rousseau F, Friedman JM. "I want to know what's in Pandora's Box": comparing stakeholder perspectives on incidental findings in clinical whole genome sequencing. Am J Med Genet. 2012;158A(10):2519-25.

20 Bijlsma RM, Wessels H, Wouters RHP, May AM, Ausems MGEM, Voest EE, et al. Cancer patients' intentions towards receiving unsolicited genetic information obtained using next-generation sequencing. Fam Cancer. 2018;17(2):309-16.

21 McGuire AL, Oliver JM, Slashinski MJ, Graves JL, Wang T, Kelly PA, et al. To Share or not to share: a randomized trial of consent for data sharing in genome research. Genet Med. 2011;13(11):948-55.

22 Genome England [Internet]. What is a genome? [cited 2020 June 6]. Available from: https://www.genomicsengland.co.uk/the100000-genomes-project/understanding-genomics/what-is-a-genome/.

23 National Human Genome Research Institute [Internet]. Frequently asked questions about pharmacogenomics [cited 2020 June 6]. Available from: https://www.genome.gov/ 27530645/faq-about-pharmacogenomics/

24 Sandelowski M. What's in a Name? Qualitative description revisited. Res Nurs Health. 2010;33(1):77-84.

25 Glaser B, Straus A. The discovery of grounded theory: strategies for qualitative research. New York, NY: Routledge; 2017.

26 Collins FS, Varmus H. A new initiative on precision medicine. N Engl J Med. 2015; 372(9):793-5.

27 Haga SB, O’Daniel JM, Tindall GM, Lipkus IR, Agans R. Survey of US public attitudes toward pharmacogenetic testing. Pharmacogenomics J. 2012;12(3):197-204.

28 Fargher EA, Eddy C, Newman W, Qasim F, Tricker K, Elliott RA, et al. Patients' and healthcare professionals' views on pharmacogenetic testing and its future delivery in the NHS. Pharmacogenomics. 2007;8(11):1511-

29 Haddy CA, Ward HM, Angley MT, McKinnon RA. Consumers' views of pharmacogenetics: a qualitative study. Res Social Adm Pharm. 2010;6(3):221-31.

30 Trinidad S, Coffin T, Fullerton S, Ralston J, Jarvik G, Larson E. 'Getting off the bus closer to your destination': patients' views on pharmacogenomic testing. Perm J. 2015;19(3):21-7.

31 McEwen JE, Boyer JT, Sun KY. Evolving approaches to the ethical management of genomic data. Trends Genet. 2013;29(6):37582.

32 Genetic Alliance UK. Genome sequencing: What do patients think? Patient Charter [cited 2020 Jun 30]. Available from: https://www. geneticalliance.org.uk/media/1924/patientcharter-genome-sequencing-what-do-patients-think.pdf.

33 Etchegary H, Power A. Your data, your choice. A design jam on modernizing healthcare consent models to unlock health inno- vation. [cited 2020 Jun 30]. Available from: http://www.mun.ca/bioethics/DJR.pdf.

34 Budin-Ljosne I, Teare HJA, Kaye J, Beck S, Bentzen HB, Caenazzo L, et al. Dynamic consent: a potential solution to some of the challenges of modern biomedical research. BMC Med Ethics. 2017;18:4.

35 Ball MP, Bobe JR, Chou MF, Clegg T, Estep PW, Lunshof JE, et al. Harvard personal genome project: lessons from participatory public research. Genome Med. 2014;6(2):10.

36 Veilleux S, Bouffard M, Bourque Bouliane M Patient and health care provider needs and preferences in understanding pharmacogenomic and genomic testing: a meta-data analysis. Qual Health Res. 2020;30(1):43-59.

37 Haga SB, Burke W, Agans R. Primary care physicians' access to genetic specialists: an impediment to the routine use of genomic medicine? Genet Med. 2013;15(7):513-4.

38 Hynes J, MacMillan A, Fernandez S, Jacob K, Carter S, Predham S, et al. Group plus "mini" individual pre-test genetic counselling sessions for hereditary cancer shorten provider time and improve patient satisfaction. Hered Cancer Clin Pract. 2020;18:3.

39 Yuen J, Cousens N, Barlow-Stewart K, O’Shea $\mathrm{R}$, Andrews L. Online BRCA1/2 screening in the Australian Jewish community: a qualitative study. J Community Genet. 2020;11(3): 291-302.

40 Shaver LG, Khawer A, Yi Y, Aubrey-Bassler $\mathrm{K}$, Etchegary $\mathrm{H}$, Roebothan $\mathrm{B}$, et al. Using facebook advertising to recruit representative samples: feasibility assessment of a cross-sectional survey. J Med Internet Res. 2019;21(8): e14021.

41 Statista. Frequency of use of facebook products and services in Canada as of March 2018, by region. 2018 [cited Jan 8 2021]. Available from: https://www.statista.com/statistics/ $822150 /$ canada-facebook-products-servicesuse-by-region/.

42 Smit AK, Reyes-Marcelino G, Keogh L, Dunlop K, Newson AJ, Cust AE. Implementation considerations for offering personal genomic risk information to the public: a qualitative study. BMC Public Health. 2020;20(1):1028. 